\title{
Sığırlarda Sol Taraflı Abomasum Deplasmanlarının Yemlere Zeolit Minerali Katılarak Önlenmesi**
}

\author{
Gürbüz AKSOY ${ }^{1}{ }^{*}$, Halil Selçuk BíRicik², Mehmet AVCl ${ }^{3}$, Aydın DAŞ ${ }^{4}$ \\ ${ }^{1}$ Harran Üniversitesi, Veteriner Fakültesi, iç̧ Hastalıkları Anabilim Dalı, Şanlıurfa, Türkiye. \\ ${ }^{2}$ Afyon Kocatepe Üniversitesi, Veteriner Fakültesi, Laboratuvar Hayvanları Anabilim Dalı, Afyonkarahisar, Türkiye. \\ ${ }^{3}$ Harran Üniversitesi, Veteriner Fakültesi, Hayvan Besleme ve Beslenme Hastalıkları Anabilim Dalı, Şanlıurfa, Türkiye. \\ ${ }^{4}$ Harran Üniversitesi, Veteriner Fakültesi, Zootekni Anabilim Dalı, Şanlıurfa, Türkiye.
}

Geliş Tarihi: 19.01.2018

Kabul Tarihi: 07.05.2018

\begin{abstract}
Özet: Abomasum deplasmanlarının patogenezisinde gaz birikimi anahtar rol oynamaktadır. Zeolit, gazları absorbe eden doğal bir mineraldir. Bu çalışmanın amacını, sığırlarda yemlere katılan zeolit mineralinin sol taraflı abomasum deplasmanı insidansına ve bazı biyokimyasal parametreler üzerine olan etkisini incelemek oluşturmuştur. İlk aşamada, yemlerine zeolit katılmayan 10 adet (Kontrol-1 Grubu) ve yemlerine \% 2.5 oranında zeolit katılan 10 adet (Deneme-1 Grubu) toplam 20 sığırda bazı hematolojik, serum biyokimyasal parametreler ve rumen metabolitleri incelenmiştir. Yeme zeolit katılan grupta kolesterol ve fosfor düzeyleri kontrol grubuna göre düşük $(P<0.05)$, kalsiyum düzeyi ise yüksek $(P<0.05)$ bulunmuştur. Ayrıca, rumen sIVISı amonyak düzeyinde kontrol grubuna göre $\mathrm{P}<0.05$ düzeyinde azalma tespit edilmiştir. íkinci aşamada zeolit mineralinin sığırlarda abomasum deplasmanı insidansına etkisi incelenmiş; yemlerine zeolit katılmayan 60 adet sığırda (Kontrol-2 Grubu) 2 hayvanda sol taraflı abomasum deplasmanı olgusu ortaya çıkarken, yemlerine \% 2.5 oranında zeolit katılan 120 hayvanda (Deneme-2 Grubu) bu hastalığa rastlanmamıştır. Sonuç olarak, çalışma kapsamında incelenen parametreler açısından sığırlarda rasyona ilave edilen zeolitin herhangi bir yan etkisinin olmadığı; sol taraflı abomasum deplasmanı ve hipokalsemi oluşma riskini azalttığı, rumen hareketlerini ve iştahı arttırdığı kanısına varılmıştır.
\end{abstract}

Anahtar Kelimeler: Abomasum deplasmanı, Profilaksi, Zeolit, Sığır.

\section{Prevention of Left Displacements of the Abomasum in Cattle by Adding Zeolite Mineral to Feeds}

Abstract: Gas accumulation plays a key role in the pathogenesis of abomasum displacements. Zeolite is a natural gas adsorbing mineral. The aim of this study was to investigate the effects of zeolite addition to feeds in cattle on incidence of left displaced abomasum and some biochemical parameters. In the first step, the effects of zeolite minerals were investigated on the hematological, serum biochemical parameters and rumen metabolites in a total of 20 cattle. Trial Group-1(n=10) was fed with a ration supplemented with zeolite at 2.5 percent while Control Group-1 consumed a ration without zeolite supplementation. Cholesterol and phosphorus levels were lower $(P<0.05)$ and calcium levels were higher $(P<0.05)$ in the trial group to compared control group. In addition, zeolite lowered the ammonia level in the rumen fluid $(P<0.05)$. In the second step, the effect of zeolite mineral supplementation on the incidence of abomasum displacement in cattle was investigated. Among 60 animals fed with a ration without zeolite supplementation (Control Group -2) left-sided abomasum displacement was observed in two animals While abomasum displacement was not observed among 120 animals (Trial-2 Group) consumed a ration supplemented with zeolite at 2.5 per cent. As a result, in terms of the parameters examined in the study; zeolite addition to feed hasn't any side effect, decrease the risk of occurrence of left-sided abomasal displacement and hypocalcemia, increase ruminal movements and appetite.

Keywords: Abomasal displacement, Prophylaxis, Zeolite, Cattle.

\section{Giriş}

Abomasum deplasmanları, sığırlarda görülen en önemli metabolik kökenli hastalıklardan birisidir. Sol taraflı abomasum deplasmanı; normalde karın boşluğunun sağ ventralinde yer alan abomasumun, özellikle gaz ile dolarak abdomenin sol üst kısmına doğru hareket etmesi ve karın duvarı ile rumen arasına gelip yerleşmesidir (Rosenberger, 1990). Abomasum deplasmanının insidansı ülkeden ülkeye değişmekle birlikte, ortalama \% 0-7 arasında seyretmektedir (Kelton ve ark., 1998). Bir ülkede, hastalığın insidansı açısından sürü düzeyinde büyük farklılıklar gözlenebilmektedir. Öyle ki, bazı sürülerde sadece bir vakaya rastlanırken, diğer çiftliklerde bu oran \% 20'ye kadar çıkmaktadır (Dawson ve ark., 1992; Rosenberger, 1990). Bu durum, hastalığın ortaya çıkmasında beslenme faktörlerinin önemini göstermektedir. Bir abomasum deplasmanı vakasının getirdiği ekonomik kayıp yaklaşık olarak 250 - 450 dolar arasında değişmektedir. Kuzey Amerika'da yapılan bir araştırmada, adı geçen hastalığa bağlı olarak hesaplanan yıllık kaybın 220 milyon dolara ulaştığı bildirilmektedir (Geishauser ve ark., 2000). 
Hastalığın nedenleri multifaktoriyel olup, abomasum atonisi ve gaz oluşumu deplasmanın gelişmesine ön ayak olmaktadır. Abomasum gazla dolu olduğunda, musküler katı tonusunu kaybetmekte, biriken gazın da etkisiyle organ rumenin sol tarafına doğru yer değiştirmektedir. Hastalığın oluşumunda rol oynayan diğer faktörler olarak; hipokalsemi, mastitis, metritis, ketozis gibi hastalıklar, intraabdominal organların pozisyonundaki değişiklikler ve genetik yatkınlık sayılabilir. Olgulara çoğunlukla, 'geçiş periyodu' olarak tanımlanan doğum öncesi 2 hafta ile doğum sonrası 2-4 hafta arasında rastlanmaktadır (Zadnik ve ark., 2001). Klinik semptomlar olarak; iştahsızlık, süt veriminde ani ve hızlı düşüşler, zayıflama, sol karın duvarında asimetri, gaitanın koyu renkte ve camcı macunu gibi yapışkan kıvamda olması sayılabilir. Bununla birlikte, semptomsuz seyreden vakalar dahi bildirilmektedir. Hastalığın tanısı; sol karın duvarında aynı anda yapılan oskültasyon-perküsyon muayenesinde, karakteristik ping seslerinin alınması esasına dayanır (Rosenberger, 1990; Zadnik ve ark., 2001). Yüksek verimli süt sığırlarında yaygın olarak görülen abomasum deplasmanlarının patogenezisinde kaba yemlerin az, konsantre yemlerin fazla verilmesi gibi beslenme faktörleri ön plandadır. Hastalığın önlenmesinde alınabilecek en iyi tedbir, yemlemenin kontrolüdür. 'Geçiş dönemi' olarak adlandırılan doğum öncesi 2 hafta ile doğum sonrası 4 hafta arasında konsantre yem / kaba yem oranı artırımamalı; kaba lif oranı \% $18-20$ dolaylarında olmalıdır (Aksoy, 2014; Rosenberger, 1970; Van Winden ve ark., 2003). Bununla birlikte profilakside henüz etkili bir önlem geliştirilememiştir. Tedavide, konservatif olarak ilk kez 1956 yılında Begg ve Whiteford tarafından geliştirilen yuvarlama yöntemi uygulanmaya başlanmıştır. Yuvarlamada hayvan sağ tarafına yatırılarak, ön ve arka ayaklar bağlanır. Daha sonra yavaşça sağdan sola, soldan sağa çevrilerek sol tarafından ayağa kaldırılır. Bu yöntemde; abomasum yerine yerleşmekte, ancak olguların \% 80'inde kısa süre içinde nüksler görülmektedir. Bu nedenle, günümüzde artık pek tercih edilmemektedir. Operatif tedavide ise açık ya da kapalı (perkutan) teknikler kullanılmaktadır (Rosenberger, 1990). Bütün tedavi yöntemlerinde temel amaç olarak; içindeki gazın boşaltılması sonrası abomasumun normal anatomik pozisyonuna getirilmesi ve nükslerin önlenmesi için, organın ventral karın duvarına daimi şekilde tesbiti yer almaktadır. Literatürde, abomasumun fikzasyonu için, laparatomi eşliğinde ya abomasopeksi (ventral laparotomi ile abomasopeksi, endoskopi eşliğinde abomasopeksi, sağ paramedian abomasopeksi, sol paramedian abomasopeksi, sol paralumbar abomasopeksi) ya da omentopeksi (sağ taraflı laparatomi ile caudo ventral omentopeksi/Hannover metodu, sol taraflı laparatomi ile ventral
omentopeksi/Utrecht metodu) önerilmektedir (Aksoy ve ark., 1989; Popdecan ve Popdecan, 2001). Yukarıda bildirilen yöntemlere ek olarak; laparatomi yapılmaksızın abomasumun fikzasyonu esasına dayanan perkutan abomasopeksi (Grymer-Sterner) yöntemi geliştirilmiştir (Grymer ve Sterner, 1982). Yöntem, ilk defa 1982 yılında Amerika'da Grymer ve Sterner adlarında iki Veteriner Hekim tarafından uygulanmış olup, literatürde Grymer-Sterner, perkutan paramedian abomasopeksi, perkutan abomasopeksi, toggle pin fikzasyon, Grymer-Sterner toggle dikiş yöntemi, toggle dikişi olarak da adlandırılmaktadır (Grymer ve Sterner, 1982; Popdecan ve Popdecan, 2001). Operasyon yöntemlerinin pahalı olması yanında uzmanlık gerektirdiği dikkate alındığında abomasum deplasmanı hastalıklarının oluşmadan önlenmesi konusu çok daha önem kazanmaktadır.

Zeolit, ilk defa 1756 yılında İsveçli bilim adamı Frederich Cronstdet tarafından bulunmuştur. Zeolit minerallerinin en önemli özelliği sıvı ve gaz moleküllerinin, bünyesindeki boşluklara kolayca alabilmesidir. Bu nedenle, birçok gazları, petro kimyasalları, ağır metalleri, düşük seviyeli radyo aktif elementleri ve çeşitli solusyonları emme ve çekme kapasitesine sahiptir. Gübrelerin kötü kokusunun giderilmesinde, asit volkanik toprakların pH'sının yükseltilmesinde kullanılmaktadır. Yemlerine zeolit ilave edilen tavuk, domuz ve geviş getiren hayvanların, normal yemlerle beslenenlere oranla, sağlıkları bozulmaksızın ağırlıklarının arttığı belirlenmiştir (Altan ve ark., 1998; Balevi ve ark., 1998). Zeolitin ruminant beslenmesinde yararlı etkisi $\mathrm{Na}, \mathrm{Mg}, \mathrm{K}, \mathrm{Ca}$ gibi elementleri içeren bir madde olması yanında azotlu bileşiklerin sindirimi esnasında oluşan fazla amonyağı absorbe ederek daha sonra kontrollü biçimde salıvermesiyle rumendeki mikroorganizmaların, devamlı ve daha kontrollü bir biçimde protein sentezlemesini sağlamasıyla olmaktadır (Demirel, 2010). Türkiye, doğal zeolit kaynakları bakımından zengin bir ülkedir. Ülkemizde mevcut zeolit rezervlerinin $\mathbf{4 5 . 8}$ milyar ton gibi büyük hacimlerde olduğu tespit edilmiştir (Altan ve ark., 1998). Uygulama alanları itibariyle birçok sektörü ilgilendiren zeolitler, gerek bilimsel ve gerekse ticari uygulamalar açısından yer bilimleri, kimya, fizik, ziraat, hayvancılık ve tıbbın ilgi alanına girmiş bulunmaktadır. Molekül yapılarında bulunan boşluklar ve elektrik yüklerinden dolayı absorban özelliği taşıyan zeolitin yüksek bir amonyak absorbsiyon kapasitesine sahip olduğu bilinmekte; nem emici özelliğinden dolayı gübrelerde depolama sırasında oluşan pişme ve sertleşmeyi önlemektedir (Altan ve ark., 1998; Balevi ve ark., 1998; Demirel, 2010). Yapılan bir çalışmada gebeliğin son döneminde olan süt ineklerinin günlük rasyonlarına zeolit ilavesinin, hipokalsemi oluşum riskini belirgin derecede azalttığı tespit edilmiştir (Hansen ve 
Jorgensen, 2001). Hipokalsemide abomasum düz kaslarında nöromuskuler ileti bozukluğuna bağlı hipomotilite şekillenmekte ve bu durum deplasman oluşum riskini artırmaktadır. Abomasumda gaz birikimi ve motilite azalması sonucunda organ yer değiştirmektedir. Zeolitin gaz emici ve iştah artırıcı, ayrıca hipokalsemiyi önleyici etkisi göz önüne alındığında, bu mineralin söz konusu hastalığın profilaksisinde etkili olabileceği düşünülmektedir.

$\mathrm{Bu}$ çalışmada; sığırlarda yeme katılan zeolit mineralinin hematolojik, serum biyokimyasal, rumen parametrelerini değerlendirmek suretiyle, saha koşullarında abomasum deplasmanı insidansına etkisini araştırmak amaçlanmıştır.

\section{Materyal ve Metod}

Çalışma; 2 aşamada yapıldı.

1. Aşama: Sığırlarda yeme katılan zeolit mineralinin hematolojik, serum biyokimyasal parametreler ve rumen metabolitleri üzerine etkisinin araştırılması,

2. Aşama: Zeolit'in sahada uygulanarak, sığırlarda abomasum deplasmanı insidansına etkisinin incelenmesi.

$\mathrm{Bu}$ plana uygun olarak; 3-8 yaşlar arasında, prepartum 3 ay ile postpartum 5 aylık dönemde bulunan 20 adet (10 adet Kontrol-1 ve 10 adet Deneme-1) Holştayn süt sığırında, 3 ay süreyle Zeolit minerali (Rotamin, Rota Madencilik, Gördes, Manisa) \% 2.5 oranında yeme katıldı (Deneme-1 grubu). Rasyonlar hazırlanırken hayvanların ihtiyaçları NRC 2001'e göre hesaplanmıştır. Rasyonların bileşimi ve içeriği Tablo 1'de verilmiştir. Süt sığırlarının 10 günde bir kez olmak üzere, rutin klinik muayeneleri (nabız, solunum, vücut sıcaklığı, rumen hareketleri, iştah, ping sesi kontrolü ve karın duvarının inspeksiyonu) yapıldı. Her iki grupta; deneme öncesi ve deneme sonrası 10 günde bir kez olmak üzere, kan örnekleri V. jugularis'ten ve rumen sıvıları ise sonda aracılığıyla rumenden alındı.

Tablo 1. Araştırmada kullanılan süt sığırı yemlerin bileşimi ve besin madde içerikleri.

\begin{tabular}{|c|c|c|}
\hline Yem Maddeleri & Kontrol (\%) & Zeolit Grubu \\
\hline Buğday Samanı & 24.04 & 20.69 \\
\hline Yonca Kuru Otu & 26.19 & 26.19 \\
\hline Arpa & 10.48 & 10.48 \\
\hline Buğday & 4.19 & 4.19 \\
\hline Mısır & 13.10 & 13.62 \\
\hline Pamuk Tohumu Küspesi & 5.24 & 5.34 \\
\hline Soya Fasulyesi küspesi & 10.48 & 10.74 \\
\hline Buğday Kepeği & 5.24 & 5.24 \\
\hline Kireç Taşı & 0.52 & 0.52 \\
\hline Tuz & 0.31 & 0.31 \\
\hline Mineral-vitamin premix & 0.21 & 0.21 \\
\hline Zeolit & --- & 2.50 \\
\hline Besin Madde içeriği & $\%$ & $\%$ \\
\hline Kuru Madde (KM) & 90.73 & 90.88 \\
\hline Ham Protein (\% KM) & 18.15 & 18.15 \\
\hline * Metabolik Enerji (Mcal/kg KM) & 2.35 & 2.34 \\
\hline * Net Enerji Laktasyon (Mcal/kg KM) & 1.47 & 1.46 \\
\hline Kalsiyum (\% KM) & 0.74 & 0.73 \\
\hline Fosfor (\% KM) & 0.37 & 0.37 \\
\hline Nötral Deterjan Fiber & 38.43 & 35.99 \\
\hline Asit Deterjan Fiber (\% KM) & 24.82 & 23.17 \\
\hline
\end{tabular}

*Hesaplanan.

Hematolojik parametreler (hematokrit, hemoglobin, eritrosit ve lökosit sayıları) Ca-610 Model (Stockholm Sweden) otomatik kan sayım cihazında tespit edildi. Kan serumunda ise; AST, ALT, GGT, glukoz, total bilirubin, kolesterol, üre, kreatinin, $\mathrm{Ca}, \mathrm{Mg}, \mathrm{P}, \mathrm{Na}, \mathrm{K}, \mathrm{Cl}$, total protein, albumin ve amonyak olmak üzere toplam 17 parametrenin analizleri Cobas Integra 800 (Roche) oto-analizörü ile ölçüldü. Serum NEFA (esterleşmemiş uçucu yağ asidi) ise, NEFA-C ticari kitleri kullanılarak spektrofotometrede enzimatik kolorimetrik yöntemle tayin edildi. 20 sığırdan (10 adet Kontrol-1 ve 10 adet Deneme-1) alınan 200 adet rumen sIvisı örneğinde, propiyonik asit, asetik asit ve bütirik asit analizleri gaz kromatografi cihazında kapiller kolon kullanılarak yapıldı. Uçucu yağ asidi (asetik, bütirik ve propiyonik asit) tayini için iki paralel $10 \mathrm{ml}$ rumen SIVISı 4000 devirde $15 \mathrm{dk}$ santrifüje edilerek kaba partiküllerin dibe çökmesi sağlandıktan sonra, iki paralel olan rumen sıvılarının üst kısımlarından 5 'er $\mathrm{ml}$ alınarak birleştirildi ve üzerlerine $0.5 \mathrm{ml}$ formik asit, $1.5 \mathrm{ml}$ metafosforik asit eklenerek tekrar 4000 devirde 15 dakika santrifüj edildi. Sıvının üst kısmından 3'er ml'lik iki paralel tüpe aktarılarak analizleri yapılmak üzere derin dondurucuda -20 ${ }^{\circ} \mathrm{C}^{\prime}$ de saklandı. Rumen $\mathrm{pH}$ 'sı, en geç bir saat içinde 
$\mathrm{pH}$ metre ile tespit edildi. Rumen amonyak miktarı ise, ticari kitler (Cobas Integra, Roche, Germany) kullanılarak tayin edildi.

Çalışmanın ikinci aşamasında; Zeolit sığırların yemlerine katıldı. Uygulama, sahada her birinde sırasıyla 120, 45 ve 15 hayvan bulunan üç süt sığırcılığı işletmesinde toplam 180 sığır üzerinde 8 ay boyunca sürdü ve 2 grup (Kontrol-2 ve Deneme-2) olarak yapıldı. 60 hayvanın (Kontrol-2 Grubu) yemine zeolit katılmazken, 120 hayvanın (Deneme-2 Grubu) yemine zeolit katıldı. Her iki gruptaki sı̆̆ırlar, abomasum deplasmanı yönünden 8 ay boyunca klinik bulgu açısından izlendi.

İstatistiksel analizler; SPSS paket programında GLM (General Linear Model) kullanılarak yapıldı.

\section{Bulgular}

Çalışmanın birinci aşamasında, süt sığırlarında yeme katılan zeolit mineralinin hematolojik parametreler (eritrosit, lökosit, hematokrit ve hemoglobin) üzerine etkisi Tablo 2'de, serum biyokimyasal parametreler (glukoz, üre, kreatinin, total protein, albumin, kolesterol, AST, ALT, GGT, total bilirubin, $\mathrm{Ca}, \mathrm{P}, \mathrm{Mg}, \mathrm{Na}, \mathrm{K}, \mathrm{Cl}, \mathrm{NEFA}$, amonyak) üzerine etkisi Tablo 3 'de verilmiştir. Tablo 2'deki hematolojik değerlerde gruplar arasında istatistiki açıdan önemli bir fark bulunmamıştır. Tablo 3'deki laboratuar bulguları irdelendiğinde, rasyona zeolit katılan Deneme-1 Grubunda kolesterol ve fosfor düzeylerinin Kontrol-1 Grubuna göre daha düşük $(P<0.05)$, kalsiyum düzeyinin ise daha yüksek $(P<0.05)$ olduğu, diğer serum parametrelerinde ise istatistiki önemde bir değişiklik bulunmadığı görülmektedir. Yeme katılan zeolitin rumen metabolitleri (asetik asit, propiyonik asit, bütirik asit, amonyak, klor ve pH) üzerine etkisi, Tablo 4'te gösterilmiştir. Buna göre, zeolit mineralinin yeme katıldığı grupta (Deneme-1) rumen sıvısı amonyak düzeyi, kontrol hayvanlarına göre (Kontrol-1) istatistiki olarak düşük $(P<0.05)$ bulunmuştur. Zeolitin diğer rumen parametreleri üzerinde istatistiki önemde etkisi bulunamamıştır.

Tablo 2. Rasyona zeolit ilavesinin süt sığırlarında hematolojik parametreler üzerine etkisi.

\begin{tabular}{|c|c|c|c|c|c|}
\hline & Gruplar & HCT (\%) & $\mathrm{Hb}(\mathrm{g} / \mathrm{dl})$ & $R B C\left(\mathrm{~m} / \mathrm{mm}^{3}\right)$ & $W B C\left(\mathrm{~m} / \mathrm{mm}^{3}\right)$ \\
\hline \multirow{2}{*}{ Den.Ön. } & Kontrol-1 & $28,19 \pm 0,82$ & $9,37 \pm 0,23$ & $6,34 \pm 0,28$ & $7,41 \pm 0,31$ \\
\hline & Deneme-1 & $29,79 \pm 0,82$ & $9,60 \pm 0,23$ & $6,49 \pm 0,28$ & $7,64 \pm 0,31$ \\
\hline \multirow{2}{*}{ 10.gün } & Kontrol-1 & $29,49 \pm 0,68$ & $9,67 \pm 0,24$ & $6,58 \pm 0,18$ & $7,51 \pm 0,31$ \\
\hline & Deneme-1 & $29,61 \pm 0,68$ & $9,63 \pm 0,24$ & $6,75 \pm 0,18$ & $7,62 \pm 0,31$ \\
\hline \multirow{2}{*}{ 20.gün } & Kontrol-1 & $29,14 \pm 0,94$ & $9,62 \pm 0,22$ & $6,56 \pm 0,19$ & $7,73 \pm 0,32$ \\
\hline & Deneme-1 & $28,85 \pm 0,94$ & $9,63 \pm 0,22$ & $6,26 \pm 0,19$ & $7,65 \pm 0,32$ \\
\hline \multirow{2}{*}{ 30.gün } & Kontrol-1 & $29,10 \pm 0,96$ & $9,59 \pm 0,18$ & $6,52 \pm 0,24$ & $7,78 \pm 0,36$ \\
\hline & Deneme-1 & $28,35 \pm 0,96$ & $9,70 \pm 0,18$ & $6,33 \pm 0,24$ & $7,70 \pm 0,36$ \\
\hline \multirow{2}{*}{ 40.gün } & Kontrol-1 & $29,09 \pm 1,01$ & $9,61 \pm 0,18$ & $6,56 \pm 0,19$ & $7,67 \pm 0,33$ \\
\hline & Deneme-1 & $29,90 \pm 1,01$ & $9,75 \pm 0,18$ & $6,58 \pm 0,19$ & $7,64 \pm 0,33$ \\
\hline \multirow{2}{*}{ 50.gün } & Kontrol-1 & $29,80 \pm 1,00$ & $9,55 \pm 0,19$ & $6,41 \pm 0,33$ & $7,60 \pm 0,40$ \\
\hline & Deneme-1 & $30,18 \pm 1,00$ & $9,74 \pm 0,19$ & $6,55 \pm 0,33$ & $7,61 \pm 0,40$ \\
\hline \multirow{2}{*}{ 60.gün } & Kontrol-1 & $28,77 \pm 0,89$ & $9,65 \pm 0,14$ & $6,69 \pm 0,26$ & $7,56 \pm 0,34$ \\
\hline & Deneme-1 & $29,98 \pm 0,89$ & $9,66 \pm 0,14$ & $6,51 \pm 0,26$ & $7,41 \pm 0,34$ \\
\hline \multirow{2}{*}{ 70.gün } & Kontrol-1 & $28,30 \pm 1,10$ & $9,46 \pm 0,12$ & $6,65 \pm 0,26$ & $7,54 \pm 0,40$ \\
\hline & Deneme-1 & $30,32 \pm 1,10$ & $9,66 \pm 0,12$ & $6,66 \pm 0,26$ & $7,60 \pm 0,40$ \\
\hline \multirow{2}{*}{ 80.gün } & Kontrol-1 & $29,10 \pm 0,96$ & $9,53 \pm 0,11$ & $6,61 \pm 0,22$ & $7,40 \pm 0,33$ \\
\hline & Deneme-1 & $31,30 \pm 0,96$ & $9,72 \pm 0,11$ & $6,44 \pm 0,22$ & $7,47 \pm 0,33$ \\
\hline \multirow{2}{*}{ 90.gün } & Kontrol-1 & $30,64 \pm 0,89$ & $9,45 \pm 0,13$ & $6,61 \pm 0,23$ & $7,52 \pm 0,37$ \\
\hline & Deneme-1 & $31,09 \pm 0,89$ & $9,62 \pm 0,13$ & $6,65 \pm 0,23$ & $7,57 \pm 0,37$ \\
\hline \multirow{2}{*}{ Total } & Kontrol-1 & $29,16 \pm 0,66$ & $9,55 \pm 0,10$ & $6,55 \pm 0,09$ & $7,57 \pm 0,13$ \\
\hline & Deneme-1 & $29,94 \pm 0,66$ & $9,67 \pm 0,10$ & $6,52 \pm 0,09$ & $7,59 \pm 0,13$ \\
\hline $\mathbf{P}$ & & NS & NS & NS & NS \\
\hline
\end{tabular}

Çalışmanın ikinci aşamasında saha şartlarında yemlerine zeolit katılmayan 60 sığırda (Kontrol-2 Grubu), 2 hayvanda sol taraflı abomasum deplasmanı olgusu saptanırken (\% 3.3), zeolit katılan 120 sığırda (Deneme-2 Grubu) ise abomasum deplasmanı olgusuyla karşılaşılmadı. Gerek birinci aşamada, gerekse ikinci aşamada yemlerine zeolit katılan sığırlarda rumen hareketlerinin sayısının \% 10-30 oranında arttığı dikkati çekti. Hayvan sahipleriyle yapılan görüşmelerde de zeolitin hayvanların iştahını bariz olarak artırdığı bilgisine ulaşıldı. 
Tablo 3. Rasyona zeolit ilavesinin süt sığırlarında bazı serum biyokimyasal parametreleri üzerine etkisi.

\begin{tabular}{|c|c|c|c|c|c|c|}
\hline & Gruplar & CRE (mg/dL) & AST (U/L) & ALT (U/L) & GGT (U/L) & BIL-T (mg/dL) \\
\hline \multirow{2}{*}{ Den.Ön. } & Kontrol-1 & $1,40 \pm 0,09$ & $89,00 \pm 5,17$ & $24,40 \pm 2,83$ & $25,10 \pm 1,81$ & $0,50 \pm 0,02$ \\
\hline & Deneme-1 & $1,38 \pm 0,09$ & $88,40 \pm 5,17$ & $26,00 \pm 2,83$ & $25,80 \pm 1,81$ & $0,44 \pm 0,02$ \\
\hline \multirow{2}{*}{ 10.gün } & Kontrol-1 & $1,39 \pm 0,06$ & $92,40 \pm 4,01$ & $25,10 \pm 3,16$ & $25,60 \pm 1,60$ & $0,46 \pm 0,02$ \\
\hline & Deneme-1 & $1,45 \pm 0,06$ & $87,10 \pm 4,01$ & $26,60 \pm 3,16$ & $25,50 \pm 1,60$ & $0,44 \pm 0,02$ \\
\hline \multirow{2}{*}{ 20.gün } & Kontrol-1 & $1,45 \pm 0,05$ & $85,90 \pm 5,58$ & $25,20 \pm 3,60$ & $25,60 \pm 1,66$ & $0,44 \pm 0,02$ \\
\hline & Deneme-1 & $1,48 \pm 0,05$ & $91,10 \pm 5,58$ & $25,40 \pm 3,60$ & $25,70 \pm 1,66$ & $0,47 \pm 0,02$ \\
\hline \multirow{2}{*}{ 30.gün } & Kontrol-1 & $1,49 \pm 0,08$ & $93,30 \pm 3,99$ & $26,20 \pm 4,40$ & $25,80 \pm 1,98$ & $0,49 \pm 0,03$ \\
\hline & Deneme-1 & $1,40 \pm 0,08$ & $93,40 \pm 3,99$ & $26,70 \pm 4,40$ & $25,60 \pm 1,98$ & $0,50 \pm 0,03$ \\
\hline \multirow{2}{*}{ 40.gün } & Kontrol-1 & $1,38 \pm 0,07$ & $89,90 \pm 3,25$ & $26,50 \pm 5,01$ & $26,00 \pm 1,35$ & $0,48 \pm 0,04$ \\
\hline & Deneme-1 & $1,48 \pm 0,07$ & $89,80 \pm 3,25$ & $25,10 \pm 5,01$ & $25,60 \pm 1,35$ & $0,47 \pm 0,04$ \\
\hline \multirow{2}{*}{ 50.gün } & Kontrol-1 & $1,47 \pm 0,07$ & $89,30 \pm 4,39$ & $24,60 \pm 3,61$ & $24,90 \pm 1,98$ & $0,47 \pm 0,01$ \\
\hline & Deneme-1 & $1,44 \pm 0,07$ & $92,40 \pm 4,39$ & $25,30 \pm 3,61$ & $25,20 \pm 1,98$ & $0,45 \pm 0,01$ \\
\hline \multirow{2}{*}{ 60.gün } & Kontrol-1 & $1,45 \pm 0,06$ & $92,10 \pm 5,84$ & $26,00 \pm 3,25$ & $25,50 \pm 1,91$ & $0,44 \pm 0,02$ \\
\hline & Deneme-1 & $1,44 \pm 0,06$ & $89,70 \pm 5,84$ & $25,50 \pm 3,25$ & $25,40 \pm 1,91$ & $0,48 \pm 0,02$ \\
\hline \multirow{2}{*}{ 70.gün } & Kontrol-1 & $1,39 \pm 0,10$ & $90,00 \pm 4,04$ & $25,50 \pm 3,22$ & $25,40 \pm 1,67$ & $0,48 \pm 0,05$ \\
\hline & Deneme-1 & $1,38 \pm 0,10$ & $91,70 \pm 4,04$ & $24,70 \pm 3,22$ & $25,20 \pm 1,67$ & $0,49 \pm 0,05$ \\
\hline \multirow{2}{*}{ 80.gün } & Kontrol-1 & $1,40 \pm 0,09$ & $91,30 \pm 3,14$ & $26,30 \pm 3,09$ & $25,90 \pm 1,90$ & $0,48 \pm 0,04$ \\
\hline & Deneme-1 & $1,43 \pm 0,09$ & $92,90 \pm 3,14$ & $26,50 \pm 3,09$ & $25,60 \pm 1,90$ & $0,46 \pm 0,04$ \\
\hline \multirow{2}{*}{ 90.gün } & Kontrol-1 & $1,41 \pm 0,08$ & $85,40 \pm 3,51$ & $25,90 \pm 3,39$ & $25,70 \pm 1,51$ & $0,48 \pm 0,03$ \\
\hline & Deneme-1 & $1,41 \pm 0,08$ & $91,50 \pm 3,51$ & $29,20 \pm 3,39$ & $25,40 \pm 1,51$ & $0,49 \pm 0,03$ \\
\hline \multirow{2}{*}{ Total } & Kontrol-1 & $1,42 \pm 0,03$ & $89,86 \pm 1,75$ & $25,57 \pm 1,38$ & $25,55 \pm 0,77$ & $0,47 \pm 0,01$ \\
\hline & Deneme-1 & $1,43 \pm 0,03$ & $90,80 \pm 1,75$ & $26,10 \pm 1,38$ & $25,50 \pm 0,77$ & $0,47 \pm 0,01$ \\
\hline $\mathbf{P}$ & & NS & NS & NS & NS & NS \\
\hline
\end{tabular}

NS: Önemsiz, ${ }^{*}: \mathrm{P}<0.05$.

Tablo 3. Rasyona zeolit ilavesinin süt sığırlarında bazı serum biyokimyasal parametreleri üzerine etkisi (Devamı).

\begin{tabular}{|c|c|c|c|c|c|c|c|c|}
\hline & Gruplar & $\begin{array}{l}\text { Glukoz } \\
\mathrm{mg} / \mathrm{dl}\end{array}$ & $\begin{array}{l}\text { Ure } \\
\mathrm{mg} / \mathrm{dl}\end{array}$ & $\begin{array}{l}\text { T Prot. } \\
\text { g/dl }\end{array}$ & $\begin{array}{l}\text { ALB } \\
g / d l\end{array}$ & $\begin{array}{c}\text { Kol } \\
\mathrm{mg} / \mathrm{dl}\end{array}$ & $\begin{array}{c}\text { NEFA } \\
\mathrm{mmol} / \mathrm{l}\end{array}$ & $\begin{array}{c}\mathrm{NH3} \\
\mu \mathrm{mol} / \mathrm{L}\end{array}$ \\
\hline \multirow{2}{*}{ Den.Ön. } & Kontrol-1 & $53,10 \pm 3,39$ & $15,80 \pm 2,25$ & $7,85 \pm 0,38$ & $3,67 \pm 0,14$ & $133,80 \pm 10,52$ & $0,62 \pm 0,05$ & $23,81 \pm 1,67$ \\
\hline & Deneme-1 & $50,40 \pm 3,39$ & $16,10 \pm 2,25$ & $7,99 \pm 0,38$ & $3,38 \pm 0,14$ & $133,10 \pm 10,52$ & $0,62 \pm 0,05$ & $24,05 \pm 1,67$ \\
\hline \multirow{2}{*}{ 10.gün } & Kontrol-1 & $51,30 \pm 3,25$ & $15,50 \pm 1,98$ & $7,95 \pm 0,26$ & $3,47 \pm 0,11$ & $134,20 \pm 6,33$ & $0,63 \pm 0,06$ & $23,92 \pm 1,54$ \\
\hline & Deneme-1 & $50,50 \pm 3,25$ & $16,20 \pm 1,98$ & $7,95 \pm 0,26$ & $3,63 \pm 0,11$ & $125,10 \pm 6,33$ & $0,63 \pm 0,06$ & $24,02 \pm 1,54$ \\
\hline \multirow{2}{*}{ 20.gün } & Kontrol-1 & $52,70 \pm 2,95$ & $15,60 \pm 1,88$ & $7,71 \pm 0,26$ & $3,52 \pm 0,11$ & $133,90 \pm 7,25$ & $0,62 \pm 0,05$ & $24,38 \pm 1,27$ \\
\hline & Deneme-1 & $51,50 \pm 2,95$ & $16,40 \pm 1,88$ & $7,66 \pm 0,26$ & $3,83 \pm 0,11$ & $126,10 \pm 7,25$ & $0,61 \pm 0,05$ & $23,26 \pm 1,27$ \\
\hline \multirow{2}{*}{ 30.gün } & Kontrol-1 & $51,90 \pm 3,39$ & $15,60 \pm 1,67$ & $7,94 \pm 0,46$ & $3,77 \pm 0,22$ & $133,40 \pm 4,91$ & $0,64 \pm 0,04$ & $23,77 \pm 1,80$ \\
\hline & Deneme-1 & $50,10 \pm 3,39$ & $15,90 \pm 1,67$ & $7,91 \pm 0,46$ & $3,71 \pm 0,22$ & $126,30 \pm 4,91$ & $0,63 \pm 0,04$ & $23,66 \pm 1,80$ \\
\hline \multirow{2}{*}{ 40.gün } & Kontrol-1 & $49,30 \pm 3,50$ & $15,80 \pm 1,50$ & $7,86 \pm 0,44$ & $3,82 \pm 0,12$ & $131,40 \pm 4,34$ & $0,63 \pm 0,05$ & $23,98 \pm 1,73$ \\
\hline & Deneme-1 & $49,10 \pm 3,50$ & $15,50 \pm 1,50$ & $7,46 \pm 0,44$ & $3,89 \pm 0,12$ & $122,70 \pm 4,34$ & $0,63 \pm 0,05$ & $22,82 \pm 1,73$ \\
\hline \multirow{2}{*}{ 50.gün } & Kontrol-1 & $50,70 \pm 4,56$ & $15,90 \pm 1,61$ & $7,81 \pm 0,39$ & $3,77 \pm 0,09$ & $130,30 \pm 6,96$ & $0,65 \pm 0,03$ & $23,35 \pm 1,11$ \\
\hline & Deneme-1 & $49,90 \pm 4,56$ & $16,20 \pm 1,61$ & $7,56 \pm 0,39$ & $3,81 \pm 0,09$ & $124,80 \pm 6,96$ & $0,63 \pm 0,03$ & $23,70 \pm 1,11$ \\
\hline \multirow{2}{*}{ 60.gün } & Kontrol-1 & $50,40 \pm 4,26$ & $16,10 \pm 1,57$ & $7,72 \pm 0,26$ & $3,70 \pm 0,13$ & $134,60 \pm 7,44$ & $0,65 \pm 0,03$ & $23,90 \pm 1,18$ \\
\hline & Deneme-1 & $50,50 \pm 4,26$ & $16,20 \pm 1,57$ & $7,93 \pm 0,26$ & $3,88 \pm 0,13$ & $125,30 \pm 7,44$ & $0,64 \pm 0,03$ & $23,18 \pm 1,18$ \\
\hline \multirow{2}{*}{ 70.gün } & Kontrol-1 & $51,80 \pm 3,27$ & $15,80 \pm 1,48$ & $7,56 \pm 0,24$ & $3,64 \pm 0,14$ & $132,90 \pm 5,42$ & $0,61 \pm 0,03$ & $23,59 \pm 1,58$ \\
\hline & Deneme-1 & $50,90 \pm 3,27$ & $15,90 \pm 1,48$ & $7,81 \pm 0,24$ & $3,80 \pm 0,14$ & $127,30 \pm 5,42$ & $0,62 \pm 0,03$ & $23,89 \pm 1,58$ \\
\hline \multirow{2}{*}{ 80.gün } & Kontrol-1 & $49,10 \pm 3,08$ & $16,30 \pm 0,92$ & $7,76 \pm 0,45$ & $3,84 \pm 0,13$ & $134,20 \pm 4,63$ & $0,64 \pm 0,04$ & $24,04 \pm 1,13$ \\
\hline & Deneme-1 & $52,90 \pm 3,08$ & $15,90 \pm 0,92$ & $7,74 \pm 0,45$ & $3,74 \pm 0,13$ & $125,50 \pm 4,63$ & $0,63 \pm 0,04$ & $23,53 \pm 1,13$ \\
\hline \multirow{2}{*}{ 90.gün } & Kontrol-1 & $50,40 \pm 3,59$ & $16,10 \pm 1,01$ & $7,69 \pm 0,35$ & $3,64 \pm 0,17$ & $135,60 \pm 5,77$ & $0,65 \pm 0,03$ & $24,10 \pm 0,69$ \\
\hline & Deneme-1 & $49,60 \pm 3,59$ & $15,80 \pm 1,01$ & $7,69 \pm 0,35$ & $3,78 \pm 0,17$ & $124,70 \pm 5,77$ & $0,64 \pm 0,03$ & $23,38 \pm 0,69$ \\
\hline \multirow{2}{*}{ Total } & Kontrol-1 & $51,07 \pm 0,98$ & $15,85 \pm 0,29$ & $7,79 \pm 0,12$ & $3,68 \pm 0,04$ & $133,43 \pm 2,59$ & $0,63 \pm 0,01$ & $23,88 \pm 0,41$ \\
\hline & Deneme-1 & $50,54 \pm 0,98$ & $16,01 \pm 0,29$ & $7,77 \pm 0,12$ & $3,75 \pm 0,04$ & $126,09 \pm 2,59$ & $0,63 \pm 0,01$ & $23,55 \pm 0,41$ \\
\hline$\overline{\mathbf{P}}$ & & NS & NS & NS & NS & $*$ & NS & NS \\
\hline
\end{tabular}

NS: Önemsiz. ${ }^{*}: \mathrm{P}<0.05$ 
Tablo 3. Rasyona zeolit ilavesinin süt sığırlarında bazı serum biyokimyasal parametreleri üzerine etkisi (Devamı).

\begin{tabular}{|c|c|c|c|c|c|c|c|}
\hline & Gruplar & $\begin{array}{c}\mathrm{Ca} \\
\mathrm{mg} / \mathrm{dL}\end{array}$ & $\begin{array}{c}P \\
\mathrm{mg} / \mathrm{dL}\end{array}$ & $\begin{array}{c}\mathrm{Mg} \\
\mathrm{mg} / \mathrm{dL}\end{array}$ & $\begin{array}{c}\mathrm{Na} \\
\mathrm{mmol} / \mathrm{L}\end{array}$ & $\begin{array}{c}\mathrm{K} \\
\mathrm{mmol} / \mathrm{L}\end{array}$ & $\begin{array}{c}\mathrm{Cl} \\
\mathrm{mmol} / \mathrm{L}\end{array}$ \\
\hline \multirow{2}{*}{ Den.Ön. } & Kontrol-1 & $9,83 \pm 0,20$ & $6,48 \pm 0,45$ & $2,32 \pm 0,07$ & $144,90 \pm 3,56$ & $4,60 \pm 0,17$ & $96,00 \pm 0,91$ \\
\hline & Deneme-1 & $9,87 \pm 0,20$ & $6,32 \pm 0,45$ & $2,46 \pm 0,07$ & $142,50 \pm 3,56$ & $4,58 \pm 0,17$ & $97,10 \pm 0,91$ \\
\hline \multirow{2}{*}{ 10.gün } & Kontrol-1 & $9,89 \pm 0,14$ & $6,89 \pm 0,26$ & $2,35 \pm 0,07$ & $143,10 \pm 2,97$ & $4,60 \pm 0,17$ & $95,40 \pm 1,22$ \\
\hline & Deneme-1 & $9,92 \pm 0,14$ & $6,63 \pm 0,26$ & $2,46 \pm 0,07$ & $142,10 \pm 2,97$ & $4,70 \pm 0,17$ & $97,70 \pm 1,22$ \\
\hline \multirow{2}{*}{ 20.gün } & Kontrol-1 & $9,73 \pm 0,17$ & $6,90 \pm 0,31$ & $2,60 \pm 0,08$ & $144,90 \pm 4,09$ & $4,77 \pm 0,13$ & $94,90 \pm 1,29$ \\
\hline & Deneme-1 & $9,92 \pm 0,17$ & $6,65 \pm 0,31$ & $2,56 \pm 0,08$ & $142,50 \pm 4,09$ & $4,80 \pm 0,13$ & $96,20 \pm 1,29$ \\
\hline \multirow{2}{*}{ 30.gün } & Kontrol-1 & $9,63 \pm 0,24$ & $6,86 \pm 0,18$ & $2,38 \pm 0,07$ & $142,30 \pm 3,76$ & $4,61 \pm 0,16$ & $97,40 \pm 1,28$ \\
\hline & Deneme-1 & $9,82 \pm 0,24$ & $6,54 \pm 0,18$ & $2,37 \pm 0,07$ & $141,00 \pm 3,76$ & $4,79 \pm 0,16$ & $96,30 \pm 1,28$ \\
\hline \multirow{2}{*}{ 40.gün } & Kontrol-1 & $9,86 \pm 0,20$ & $6,91 \pm 0,23$ & $2,55 \pm 0,06$ & $140,50 \pm 4,02$ & $4,68 \pm 0,13$ & $97,50 \pm 1,46$ \\
\hline & Deneme-1 & $10,02 \pm 0,20$ & $6,69 \pm 0,23$ & $2,55 \pm 0,06$ & $142,50 \pm 4,02$ & $4,70 \pm 0,13$ & $96,70 \pm 1,46$ \\
\hline \multirow{2}{*}{ 50.gün } & Kontrol-1 & $9,88 \pm 0,16$ & $6,82 \pm 0,31$ & $2,36 \pm 0,07$ & $141,80 \pm 3,61$ & $4,61 \pm 0,13$ & $98,60 \pm 1,15$ \\
\hline & Deneme-1 & $10,17 \pm 0,16$ & $6,48 \pm 0,31$ & $2,49 \pm 0,07$ & $141,40 \pm 3,61$ & $4,70 \pm 0,13$ & $96,10 \pm 1,15$ \\
\hline \multirow{2}{*}{ 60.gün } & Kontrol-1 & $9,94 \pm 0,23$ & $6,91 \pm 0,29$ & $2,50 \pm 0,09$ & $140,90 \pm 3,60$ & $4,80 \pm 0,14$ & $97,90 \pm 1,49$ \\
\hline & Deneme-1 & $10,04 \pm 0,23$ & $6,72 \pm 0,29$ & $2,49 \pm 0,09$ & $142,40 \pm 3,60$ & $4,86 \pm 0,14$ & $95,40 \pm 1,49$ \\
\hline \multirow{2}{*}{ 70.gün } & Kontrol-1 & $9,68 \pm 0,17$ & $6,95 \pm 0,29$ & $2,47 \pm 0,05$ & $140,50 \pm 3,00$ & $4,62 \pm 0,15$ & $96,50 \pm 1,37$ \\
\hline & Deneme-1 & $10,01 \pm 0,17$ & $6,63 \pm 0,29$ & $2,53 \pm 0,05$ & $141,60 \pm 3,00$ & $4,83 \pm 0,15$ & $98,30 \pm 1,37$ \\
\hline \multirow{2}{*}{ 80.gün } & Kontrol-1 & $9,63 \pm 0,19$ & $6,87 \pm 0,21$ & $2,49 \pm 0,04$ & $140,80 \pm 3,14$ & $4,69 \pm 0,12$ & $96,80 \pm 1,22$ \\
\hline & Deneme-1 & $9,97 \pm 0,19$ & $6,61 \pm 0,21$ & $2,55 \pm 0,04$ & $141,20 \pm 3,14$ & $4,83 \pm 0,12$ & $96,70 \pm 1,22$ \\
\hline \multirow{2}{*}{ 90.gün } & Kontrol-1 & $9,58 \pm 0,19$ & $6,91 \pm 0,20$ & $2,53 \pm 0,02$ & $142,40 \pm 3,80$ & $4,77 \pm 0,18$ & $96,80 \pm 1,27$ \\
\hline & Deneme-1 & $9,78 \pm 0,19$ & $6,53 \pm 0,20$ & $2,45 \pm 0,02$ & $141,00 \pm 3,80$ & $4,81 \pm 0,18$ & $95,80 \pm 1,27$ \\
\hline \multirow{2}{*}{ Total } & Kontrol-1 & $9,77 \pm 0,06$ & $6,85 \pm 0,09$ & $2,46 \pm 0,02$ & $142,21 \pm 1,41$ & $4,68 \pm 0,03$ & $96,78 \pm 0,36$ \\
\hline & Deneme-1 & $9,95 \pm 0,06$ & $6,58 \pm 0,09$ & $2,49 \pm 0,02$ & $141,82 \pm 1,41$ & $4,76 \pm 0,03$ & $96,63 \pm 0,36$ \\
\hline $\mathbf{P}$ & & $*$ & $*$ & NS & NS & NS & NS \\
\hline
\end{tabular}

NS: Önemsiz.*: P<0.05.

Tablo 4. Rasyona zeolit ilavesinin süt sığırlarında bazı rumen parametreleri üzerine etkisi.

\begin{tabular}{|c|c|c|c|c|c|c|c|c|}
\hline & Gruplar & $\begin{array}{c}\text { Asetik } \\
\mathrm{mol} / 100 \mathrm{~mol}\end{array}$ & $\begin{array}{l}\text { Propiyonik } \\
\mathrm{mol} / 100 \mathrm{~mol}\end{array}$ & $\begin{array}{c}\text { Bütirik } \\
\mathrm{mol} / 100 \mathrm{~mol}\end{array}$ & Asetik/ Prop & $\begin{array}{c}\text { Amonyak } \\
\mathrm{mmol} / \mathrm{l}\end{array}$ & $\begin{array}{c}\text { Klor } \\
\mathrm{mmol} / \mathrm{I}\end{array}$ & pH \\
\hline \multirow{2}{*}{ Den. Ön. } & Kontrol-1 & $63,76 \pm 1,69$ & $20,92 \pm 1,46$ & $11,77 \pm 0,45$ & $3,25 \pm 0,28$ & $10,96 \pm 0,65$ & $20,44 \pm 1,99$ & $6,43 \pm 0,11$ \\
\hline & Deneme-1 & $64,29 \pm 1,69$ & $20,21 \pm 1,46$ & $11,71 \pm 0,45$ & $3,32 \pm 0,28$ & $10,80 \pm 0,65$ & $20,30 \pm 1,99$ & $6,42 \pm 0,11$ \\
\hline \multirow{2}{*}{ 10. gün } & Kontrol-1 & $62,21 \pm 1,68$ & $22,02 \pm 1,52$ & $12,16 \pm 0,44$ & $2,98 \pm 0,29$ & $11,50 \pm 0,62$ & $20,95 \pm 1,48$ & $6,38 \pm 0,15$ \\
\hline & Deneme-1 & $63,65 \pm 1,68$ & $20,93 \pm 1,52$ & $11,73 \pm 0,44$ & $3,25 \pm 0,29$ & $10,83 \pm 0,62$ & $21,42 \pm 1,48$ & $6,37 \pm 0,15$ \\
\hline \multirow{2}{*}{ 20. gün } & Kontrol-1 & $64,38 \pm 1,55$ & $20,22 \pm 1,33$ & $12,04 \pm 0,31$ & $3,38 \pm 0,27$ & $10,11 \pm 0,52$ & $21,89 \pm 1,43$ & $6,53 \pm 0,13$ \\
\hline & Deneme-1 & $63,61 \pm 1,55$ & $20,63 \pm 1,33$ & $12,25 \pm 0,31$ & $3,20 \pm 0,27$ & $9,22 \pm 0,52$ & $21,16 \pm 1,43$ & $6,37 \pm 0,13$ \\
\hline \multirow{2}{*}{ 30. gün } & Kontrol-1 & $62,51 \pm 1,56$ & $21,94 \pm 1,12$ & $11,64 \pm 0,40$ & $2,95 \pm 0,24$ & $10,35 \pm 0,48$ & $20,01 \pm 1,67$ & $6,44 \pm 0,11$ \\
\hline & Deneme-1 & $63,50 \pm 1,56$ & $20,36 \pm 1,12$ & $12,13 \pm 0,40$ & $3,24 \pm 0,24$ & $9,46 \pm 0,48$ & $23,34 \pm 1,67$ & $6,42 \pm 0,11$ \\
\hline \multirow{2}{*}{ 40. gün } & Kontrol-1 & $62,71 \pm 1,43$ & $21,67 \pm 0,92$ & $11,66 \pm 0,40$ & $2,96 \pm 0,19$ & $10,95 \pm 0,56$ & $21,14 \pm 1,41$ & $6,43 \pm 0,11$ \\
\hline & Deneme-1 & $63,45 \pm 1,43$ & $20,71 \pm 0,92$ & $11,97 \pm 0,40$ & $3,14 \pm 0,19$ & $9,48 \pm 0,56$ & $20,91 \pm 1,41$ & $6,43 \pm 0,11$ \\
\hline \multirow{2}{*}{ 50. gün } & Kontrol-1 & $62,05 \pm 1,56$ & $22,72 \pm 1,17$ & $11,42 \pm 0,35$ & $2,82 \pm 0,20$ & $11,23 \pm 0,49$ & $20,10 \pm 1,13$ & $6,48 \pm 0,12$ \\
\hline & Deneme-1 & $62,82 \pm 1,56$ & $22,45 \pm 1,17$ & $11,63 \pm 0,35$ & $2,89 \pm 0,20$ & $10,28 \pm 0,49$ & $19,80 \pm 1,13$ & $6,29 \pm 0,12$ \\
\hline \multirow{2}{*}{ 60. gün } & Kontrol-1 & $61,34 \pm 1,40$ & $22,82 \pm 0,99$ & $12,14 \pm 0,33$ & $2,78 \pm 0,18$ & $10,80 \pm 0,52$ & $19,30 \pm 0,80$ & $6,47 \pm 0,12$ \\
\hline & Deneme-1 & $64,09 \pm 1,40$ & $21,12 \pm 0,99$ & $10,91 \pm 0,33$ & $3,08 \pm 0,18$ & $9,83 \pm 0,52$ & $21,98 \pm 0,80$ & $6,42 \pm 0,12$ \\
\hline \multirow{2}{*}{ 70. gün } & Kontrol-1 & $61,58 \pm 1,15$ & $22,16 \pm 0,87$ & $12,45 \pm 0,31$ & $2,82 \pm 0,14$ & $11,19 \pm 0,51$ & $21,77 \pm 1,27$ & $6,50 \pm 0,11$ \\
\hline & Deneme-1 & $62,96 \pm 1,15$ & $21,15 \pm 0,87$ & $12,05 \pm 0,31$ & $3,04 \pm 0,14$ & $10,92 \pm 0,51$ & $20,10 \pm 1,27$ & $6,35 \pm 0,11$ \\
\hline \multirow{2}{*}{ 80. gün } & Kontrol-1 & $62,36 \pm 1,28$ & $22,58 \pm 1,09$ & $11,28 \pm 0,37$ & $2,83 \pm 0,19$ & $10,92 \pm 0,50$ & $19,38 \pm 1,36$ & $6,52 \pm 0,10$ \\
\hline & Deneme-1 & $60,97 \pm 1,28$ & $22,81 \pm 1,09$ & $12,07 \pm 0,37$ & $2,76 \pm 0,19$ & $10,15 \pm 0,50$ & $20,22 \pm 1,36$ & $6,49 \pm 0,10$ \\
\hline \multirow{2}{*}{ 90. gün } & Kontrol-1 & $62,57 \pm 1,38$ & $22,26 \pm 1,19$ & $11,17 \pm 0,40$ & $2,92 \pm 0,23$ & $10,58 \pm 0,51$ & $19,25 \pm 0,87$ & $6,56 \pm 0,11$ \\
\hline & Deneme-1 & $63,23 \pm 1,38$ & $21,88 \pm 1,19$ & $11,68 \pm 0,40$ & $3,01 \pm 0,23$ & $10,03 \pm 0,51$ & $19,82 \pm 0,87$ & $6,40 \pm 0,11$ \\
\hline \multirow{2}{*}{ Toplam } & Kontrol-1 & $62,55 \pm 0,37$ & $21,93 \pm 0,28$ & $11,77 \pm 0,13$ & $2,97 \pm 0,05$ & $10,86 \pm 0,14$ & $20,42 \pm 0,40$ & $6,47 \pm 0,03$ \\
\hline & Deneme-1 & $63,26 \pm 0,37$ & $21,23 \pm 0,28$ & $11,81 \pm 0,13$ & $3,09 \pm 0,05$ & $10,10 \pm 0,14$ & $20,91 \pm 0,40$ & $6,40 \pm 0,03$ \\
\hline $\mathbf{P}$ & & NS & NS & NS & NS & & NS & VS \\
\hline
\end{tabular}

NS: Önemsiz, ${ }^{*}: \mathrm{P}<0.05$

\section{Tartışma ve Sonuç}

Beslenme faktörleri sol taraflı abomasum deplasmanlarının etiyopatogenezinde önemli bir role sahiptir (Rosenberger,1970; Van Winden ve ark., 2003). Yüksek konsantre ve düşük kaba yem oranlı beslenme, abomasum motilitesinde azalmaya ve bu organ içerisinde gaz birikimine neden olmaktadır. Günümüzde hayvan katkı yemi olarak da kullanılmaya başlayan zeolitin önemli bir özelliği, sıvı ve gaz moleküllerini, bünyesindeki boşluklara kolayca alabilmesidir (Demirel ve ark. 2010). Bu özelliğiyle 
zeolit abomazum deplasmanlarının önlenmesinde etkili olabilir. Bu konuda yerli ve yabancı her hangi bir çalışma bulunmamaktadır. Literatürde zeolitin metabolik profil üzerinde zararlı bir etkisinin olup olmadığı yönünde bazı çalışmalar (Filya ve ark. 1999; Thilsing - Hansen ve ark., 2002; Ural ve Erdoğan , 2016) bulunmakla birlikte; bugüne kadar, önemli rezerv potansiyeline sahip olan ülkemizde zeolit üzerine yapılan çalışmalar çok yetersizdir. Çalışmamızda yeme katılan zeolitin etkisi, hem hematolojik ve biyokimyasal parametreler düzeyinde hem de abomazum deplasmanı profilaksisi yönünden araştırılmıştır. Süt sığırlarında rasyona zeolit ilavesinin hematolojik ve serum biyokimyasal parametreler üzerine etkilerini yorumlayan çeşitli araştırmalarda zeolitin söz konusu parametreler üzerine önemli bir etkisinin olmadığı bildirilmektedir (Ural, 2016). Tablo 2 ve 3 incelendiğinde yaptığımız çalışmada da benzer sonuçlara ulaşıldı. Ölçümü gerçekleştirilen hematolojik (Tablo 2) ve biyokimyasal (Tablo 3) kan parametreleri, genel olarak sığırlar için bildirilen referans değerleri aralıklarında bulunmuştur (Rosenberger, 1990). Sadece, rasyona zeolit katılan Deneme-1 Grubunda kolesterol ve fosfor düzeylerinin Kontrol-1 Grubuna göre daha düşük $(P<0.05)$, kalsiyum düzeyinin ise daha yüksek $(P<0.05)$ olduğu saptandı. Kolesterol düzeyindeki azalma Deneme-1 grubundaki doğum yapan hayvanlardan kaynaklanmış olabilir. Nitekim literatürde serum kolesterol değerlerinin doğumda en düşük seviyelere indiği bildirilmektedir (Yıldız, 2005). Zeolitin safra asidi tuzlarını sindirim kanalının yüzeyinde adsorbe ettiği, böylece kan serumundaki kolesterol düzeyini düşürdüğü de belirtilmektedir (Prvulovic ve ark., (2007). Literatürde zeolit takviyesinin, plazma inorganik fosfatı baskıladığı, plazma kalsiyum seviyelerini ise önemli ölçüde artırdığı belirtilmektedir (Hansen ve Jorgensen, 2001; Thilsing ve ark., 2002) Çalışmamızda elde ettiğimiz bulguların (Tablo 3) literatür verilerine benzediği görülmektedir. Yapılan çalışmalarda süt ineklerinin günlük rasyonlarına zeolit ilavesinin, hipokalsemi oluşum riskini belirgin derecede azalttığı tesbit edilmiştir (Hansen ve Jorgensen, 2001; Thilsing ve ark., 2002). Serum kalsiyum miktarındaki artışlarda zeolitin ihtiva ettiği kalsiyumun da rolü bulunabilir (Demirel, 2010). Özellikle doğumdan hemen önce rasyondaki kalsiyumun zeolit tarafından bağlanmasıyla doğumdan sonra ineklerde plazma kalsiyumu artmakta ve hipokalsemi riski azalmaktadır. Hipokalsemide, abomasum düz kaslarında nöromuskuler ileti bozukluğuna bağlı hipomotilite şekillenmekte ve bu durum abomasum deplasmanı riskini artırmaktadır (Goff ve Horst, 1997; Rosenberger, 1970). Bu nedenlerle yeme zeolit katılmasının kan Ca düzeyini yükselterek abomasumda olası hipomotilite sebepli deplasman vakalarını önleyici olacağı düşünülmektedir.
Alumino-silikatların bir etkisi de fosforun kullanılabilirliğini azaltmasıdır. Böylece zeolit tarafından adsorblanan fosforun kandaki düzeyi azalmaktadır (Roland ve ark., 1990). Fosfor düzeyindeki azalma barsaklardaki muhtemel bir emilme problemine bağlı olabileceği gibi, dolaşımdaki paratiroid hormonun yüksek düzeyde olmasıyla da ilişkili olabilir. Çünkü bu hormonun yüksek düzeyleri fosforun böbreklerden atılımında artışa neden olmaktadır (Thilsing ve ark., 2002).Çalışmamızda zeolit mineralinin, rumen sıvısında amonyak miktarını düşürdüğü tespit edildi (Tablo 4). Bu sonuç, çeşitli araştırıcıların (Çolpan ve ark., 1995; Filya ve ark.,1999) bulgularıyla uyum içindedir. Bu sonuçlar, yeme katılan zeolitin sı̆̆ırların rumeninde oluşan amonyağın fazlasını absorbe edebilme özelliği sayesinde hayvanlarda olası amonyak toksisitesine karşı koruyucu bir etkisinin olabileceğini göstermektedir (Filya ve ark.,1999). Çalışmamızda asetik asit miktarında zeolit verilen grupta istatistik açıdan önemli olmamakla birlikte artış gözlenmiş; diğer rumen sıvısı parametrelerinde literatür verilerine (Filya ve ark.,1999) paralel şekilde gruplar arasında önemli farklılıklar bulunmamıştır (Tablo 4).

Yemlerine zeolit katılan 120 sığırda (Deneme-2) 8 aylık deneme süresince klinik olarak abomasum deplasmanına rastlanmaması yanında yemlerine zeolit katılmayan Kontrol-2 grubundaki 60 sığırın 2'sinde (\% 3.3) sol taraflı abomasum deplasmanı olgusuna rastlanması zeolitin sığırlarda abomasum deplasmanı profilaksisinde kullanma potansiyeli olduğuna işaret etmektedir. Yapılan literatür taramasında ise, zeolitin abomasum deplasmanından koruyucu etkisini inceleyen literatür bilgi tespit edilemedi. Yaptığımız diğer bir çalışmada (Aksoy ve ark., 2008), zeolit mineralinin hem sağ hem de sol tarafıı abomasum deplasmanlarının tedavisinde etkili olduğunu ve rumen hareketlerini önemli ölçüde artırdığını belirledik. Literatürde, bu çalışmanın dışında abomasum deplasmanlarının tedavisinde zeolit kullanımıyla ilgili başka bir yayına rastlanmamıştır.

Sonuç olarak; çalışmamı kapsamında değerlendirilen parametreler açısından rasyona ilave edilen zeolitin herhangi bir yan etkisinin olmadığı; sığırlarda yeme katıldığında sol taraflı abomasum deplasmanı ve hipokalsemi oluşma riskini azalttı̆̆ı, rumen hareketlerini ve iştahı arttırdığı söylenebilir.

\section{Kaynaklar}

Aksoy G, 2014: Abomasum Deplasmanı ve Torsiyonu. Türkiye Klinikleri J Vet Sci 5(3), 57-60.

Aksoy G, Biricik HS, Çamkerten I, Das A, 2008: Non-surgical treatment of abomasal displacements with zeolite in cattle. In: 25 th World Association for Buiatrics, Congress, Budapest, Hungary, pp: 27. 
Aksoy G, Gül. Y, Ünsaldı S, 1989: Abomazumun sola yer değiştirdiği bir inekte sağ açlık çukurluğundan yapılan omentopeksi tedavisi ve sonrası klinik patolojik bulgular. Türk Veteriner Hek. Derg., 3, 19-24.

Altan A, Altan Ö, Alçiçek A, Nalbant M, Akbaş Y, 1998: Tavukçulukta doğal zeolit kullanımı, 1. altlığa zeolit ilavesinin etlik piliç performansı, altık nemi ve amonyak konsantrasyonu üzerine etkileri. Ege Üniv Ziraat Fak. Derg., 35, 1-3.

Balevi T, Coşkun B, Kurtoğlu V, Umucalılar D, 1998: Etlik piliç rasyonlarına katılan zeolitin büyüme performansıyla altlığın ıslaklığı azot amonyak ve fosfor düzeyi üzerine etkisi. Vet. Bil. Derg., 14, 33-38.

Çolpan I, Yalçın S, Ergün A, Tuncer ŞD, Küçükersan K, Ünal A, Yıldız G, 1995: Zeolitin hayvan beslemede kullanılması üzerine çalışmalar. Marmara Bölgesi II. Hayvancllık Kongresi, Uludağ Üniversitesi Veteriner Fakültesi, Kirazlıyayla, Bursa.

Dawson LJ, Aalseth EP, Rice LE, Adams GD, 1992: Influence of fiber form in a complete mixed ration on incidence of left displacement abomasum in postpartum dairy cows. J. Am. Vet. Med. Assoc., 200, 1989-1992.

Demirel DŞ, Demirel D, Doran I, 2010: Doğal Zeolitlerin Hayvancılıkta Kullanım Olanakları. Harran Üniv Ziraat Fak Derg, 14(2): 13-20

Filya I, Karabulut A, Ak i, Akgündüz V, 1999: Entansif kuzu besisinde zeolit kullanılmasının kuzuların besi performansı ile bazı kan ve rumen sıvısı metabolitleri üzerine etkileri. Hayvansal Üretim, 39-48.

Geishauser T, Leslie K, Duffield T, 2000: Metabolic aspects in the etiology of displaced abomasum. Vet. Clin. North Am. Food Anim. Pract., 16, 255-265.

Goff JP, Horst RL, 1997: Phsiological changes at parturition and their relationship to metabolic disorders. J. Dairy Sci., 80, 1260-1268.

Grymer J, Sterner KE, 1982: Percutaneous fixation of left displaced abomasum, using bar suture. J. Am. Vet. Med. Assoc., 180, 1458-1461.

Hansen TT, Jorgensen RJ, 2001: Hot Topic: Prevention of parturient paresis and subclinical hypocalcemia in dairy cows by zeolite administration in the dry period. J. Dairy Sci., 84, 691-693.

Kelton DF, Lissemore KD, Martin RE, 1998: Recommendations for recording and calculating the Incidence of selected clinical diseases of dairy cattle. J. Dairy Sci., 81, 2502-2509.

Popdecan O, Podecan SH, 2001: Treatment of left abomasal displacement in dairy cattle by rolling and percutaneous paramedian abomasopexy using toggle pin fixators of cornell wood. Slov. Vet. Res., 38, 327332.

Prvulovic D, Jovanovic-Galovic A, Stanic B, Popovic M, Grubor-Lajsic G, 2007: Effects of a clinoptilolite supplement in pig diets on performance and serum parameters. Czech Journal of Animal Science, 52, 159164.

Roland DA, Rabon HW and Frost TJ, 1990: Response of commercial leghorn to sodium aliminoslicate when fed different levels and sources of available phosphorus. Poultry Sci., 69, 2157-2164.

Rosenberger G, 1970: Krankheiten des Rindes. Verlag Paul Parey. Berlin und Hamburg.

Rosenberger G, 1990: Die klinische Untersuchung des Rindes. 3. Auflage. Verlag Paul Parey. Berlin und Hamburg.

Thilsing - Hansen T, Jorgensen RJ, Enemark JMD, Larsen T, 2002: The effect of zeolite a supplementation in the dry period on periparturient calcium, phosphorus, and magnesium homeostasis. J. Dairy Sci., 85, 18551862.

Van Winden $\mathrm{SCL}$, Jorritsma $\mathrm{R}$, Müller KE, Noordhuizen JPTM, 2003: Feed ıntake, milk yield, and metabolic parameters prior to left displaced abomasum in dairy cows. J Dairy Sci., 86: 1465-1471.

Ural DA, Erdoğan H, 2016: Siyah Alaca Ineklerde Rasyona $\% 3$ ve \% 4 Klinoptilolit Takviyesinin Aminotransferaz Enzim Düzeyleri Üzerine Etkileri. Atatürk Üniv Vet. Bil. Derg. 11(3): 319-326

Yıldız H, Balıkçı E, Kaygusuzoğlu E, 2005: Ineklerde gebelik sürecinde ve erken postpartum döneminde önemli biokimyasal ve enzimatik parametrelerin araştırılması. Fırat Üniv Sağ. Bil. Derg. 19(2),137-143.

Zadnik T, Mesaric M, Reichel P, 2001: A review of abomasal displacement- clinical and laboratory experiences at the clinic for ruminants in ljubljana. Slov Vet. Res., 38, 193-208.

**Tübitak tarafından 1060038 proje numarası ve "Sığırlarda Abomasum'un Sola Deplasmanlarının Zeolit Mineraliyle Profilaksisi ve Grymer-Sterner Yöntemiyle Sağaltımı" ismiyle desteklenmiştir.

*Yazışma Adresi: Gürbüz AKSOY

Harran Üniversitesi, Eyyübiye Kampüsü, Veteriner Fakültesi, iç̧ Hastalıkları ABD, Şanlıurfa, Türkiye. e mail: gaksoy@harran.edu.tr 